\title{
aprovechamientos hidroeléctricos en el tramo superior del río SIL
}

530.9

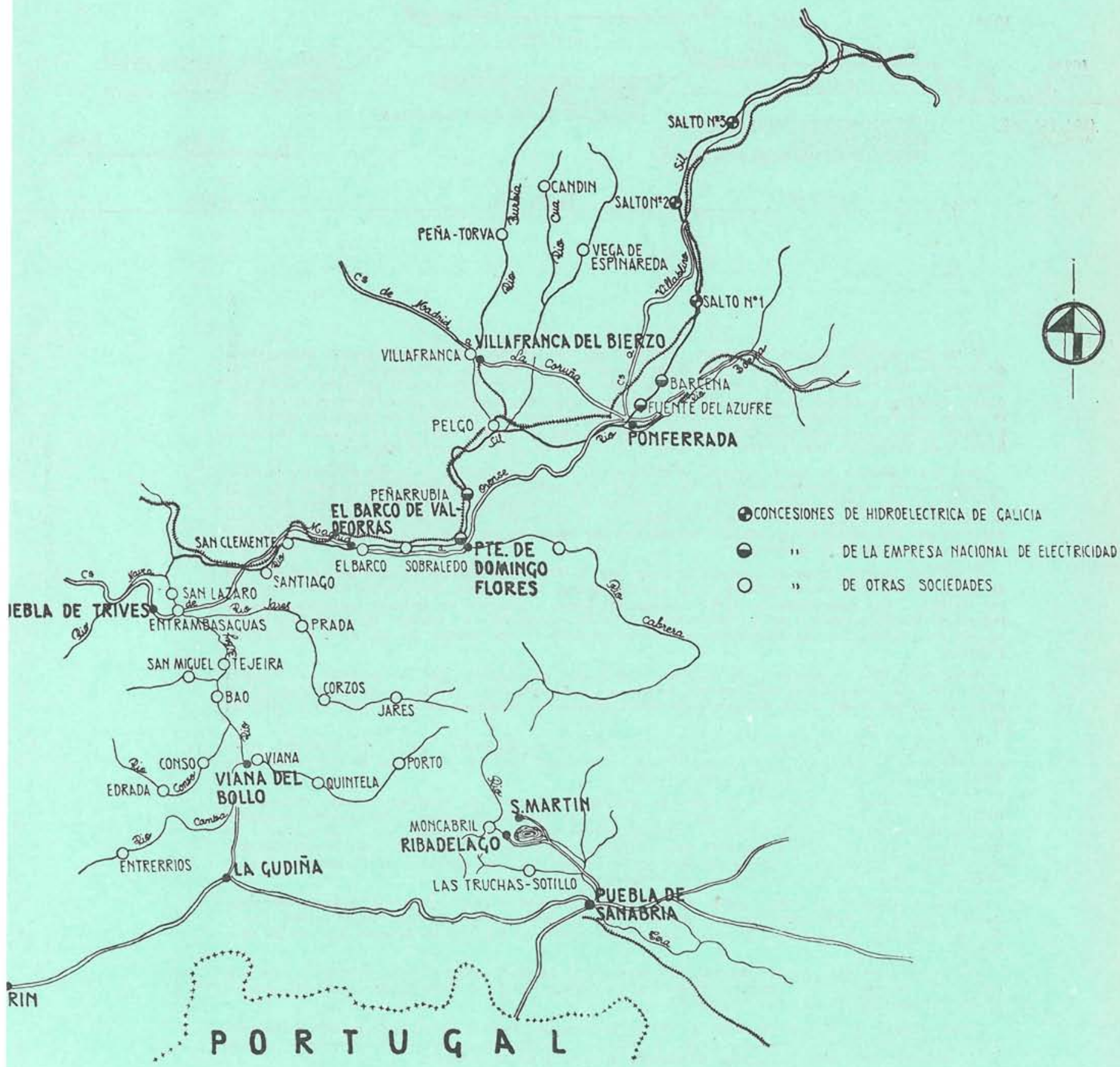

S I I N O P P S I I S

En este trabajo se describen los tres aprovechamientos hidroeléctricos, denominados Ondinas, Peñadrada y Santa Marina, dispuestos en rosario, que se extienden en el tramo superior del río Sil. Estas obras serán construidas y explotadas por la Compañia Hidroeléctrica de Galicia, empresa de este sistema ternario presenta la particularidad de tener su Central en subterráneo. 


\section{perfil longitudinal}

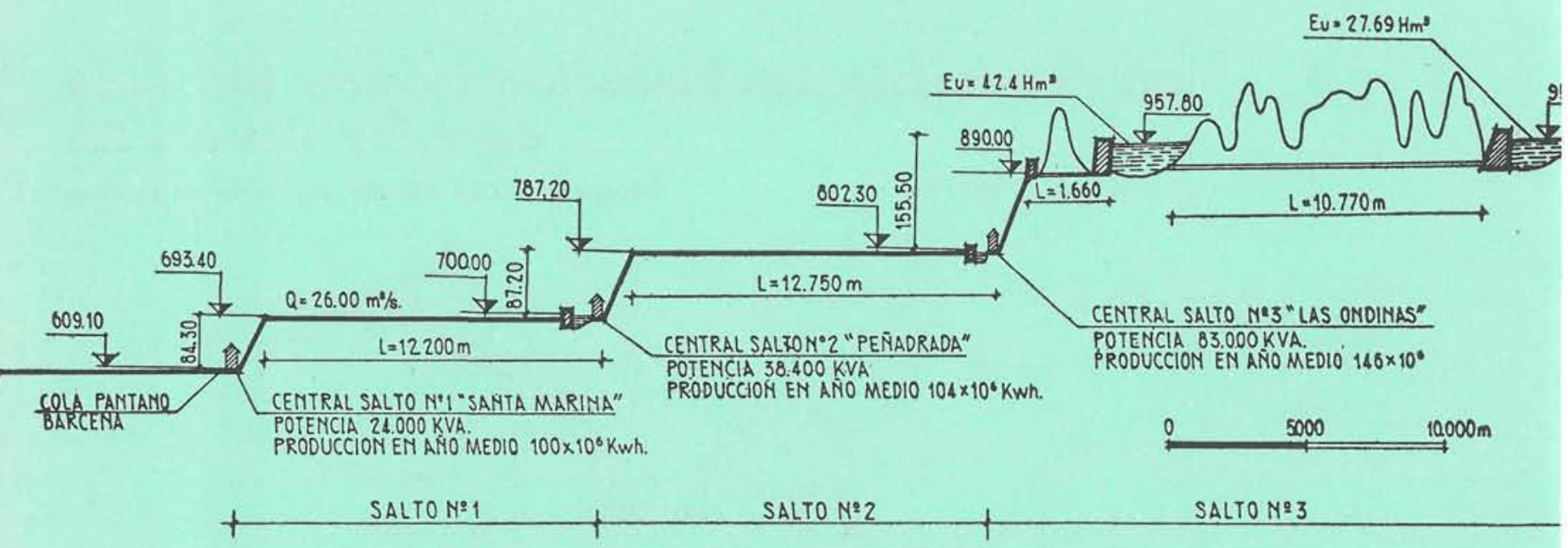

E1 rí Sil, principal afluente del Miño, constituye una de las más importantes cuencas hidrográflcas del noroeste de Espafia. Nace, con el nombre de Rioscuro, en la divisoria astur-leonesa, en el puerto de Somiedo, a $1.600 \mathrm{~m}$ de altura, y a diferencia del Miño, presenta un vigoroso perfil hidráulico, con abundantes caudales y fuertes desniveles, formando un curso de hoces y angostos pasos, poco aptos, en general, para establecer grandes embalses, pero muy indicados para la construcción de presas de derivación. Es difícil pensar en el establecimiento de zonas de regadio en su cuenca, salvo en los grandes valles del Bierzo y de Valdeorras, pero se presta fácilmente para la producción de energía eléctrica.

Nace muy próximo al Luna, cruzando inmediatamente por una planicie, en la que solamente le separan de este rio unos pequeños collados. Desde ellos se despeña en un profundo tajo, formando un codo muy pronunciado, debido, según parece, a la captación del primitivo alto Luna. Entra de esta forma en el valle de Laceana y, ya en él, cerca de Villablino, se le llama Sil, cambiando de nombre, como gran parte de los ríos espafioles, al adquirir importancia por unión de sus aguas con las procedentes de Leitariegos que le aporta el Caboalles.

El valle de Laceana forma la cabecera de su cuenca, y tiene características propias bien definidas. Se encuentra rodeado por alturas próximas a los dos mil metros, entre las que destacan las tierras, casi miticas de Babia, que constituyen la actual cabecera del Luns, y presenta un marcado contraste entre las laderas de fuertes pendientes del N., pizarrosas y desnudas, terminadas en terrazas fluvio-glaciales donde se han concentrado los más importantes núcleos de población, y las laderas del $\mathrm{S}$., de abundante vegetación.

Salvo en el NE., en contacto con el devónico de Babia, está rodeado por una importante formación carbonifera que se explota abundantemente, sacando los productos por la única vía natural, siguiendo el curso del río por medio de un ferrocarril que une Villablino con la ciudad de Ponferrada, en el valle del Bierzo.

El Sil sale del valle de Laceana encajándose en un estrecho desfladero, por el que discurre, acompańándole, en su recorrido y a su misma altura, el ferrocarril citado y la carretera de Ponferrada a La Espina, con los que se cruza en diferentes ocasiones.

El curso se desarrolla entre pizarras silúricas, atravesando manchas de cuarcitas y calizas cámbricas y llegando a la importante cuenca carbonifera de Matarrosa, después de atravesar los pequeños ensanchamientos de Palacios de Sil y de Corbón, inmediatamente anterior este último al ensanchamiento de Bárcena. La zona carbonifera se extiende desde Matarrosa a Toreno y se explota también abundantemente, aumentando el transporte de este combustible por la afluencia de las antracitas de la zona de Fabero, situada muy próxima al Sil, hacia el O., que llegan por cable aéreo.

Es región inhóspita, de tierras grises, escasa vegetación y fuertes pendientes en las laderas, con abundantes conchas de desprendimiento. El río, debido al abundante número de lavaderos de carbón instalados, discurre negro entre tierras de igual color y más merece el nombre de Rioscuro que en su nacimiento.

Toda esta parte de la cuenca ha sido solícitada por la Compañia Hidroeléctrica de Galicia para pro. ceder a su aprovechamiento, desde la unión con el Caboalles hasta el valle de Bárcena, muy próximo al gran ensanchamiento del valle del Bierzo.

Desde el valle de Bárcena se llega al del Bierzo atravesando unas manchas de granito y cuarcitas, donde se encuentran situadas las dos presas, de Bárcena y Fuente de Azufre, que constituyen el embalse y las tomas de agua para los canales de regadio del alto y del bajo Bierzo.

El Sil desemboca en este valle, con dirección NS., en las proximidades de la ciudad de Ponferrada, a pie de cuyo castillo recibe las aportaciones del Boeza. Con ellas desvía su curso en dirección EO., ciñén dose a las laderas de los montes Aquilianos, que le separan por el $\mathbf{S}$. de otro de sus grandes afluentes, el Cabrera. Surge de nuevo el contraste, entre estas laderas, con abundante vegetación de chaparros y castańos, con la margen derecha, formada por una extensa zona de escaso relieve, que forman el valle las tierras objeto del regadio.

Antes de salir de él, recibe por la margen derecha los importantes cursos de agua del Cúa Burbia y Selmo, que le incorporan las escorrentías de los picos de Ancares y Miravalles, cambiando nuevamente su dirección en NS. Junto con ellos rompe las estribaciones calizas que formarian probablemente el cierre 


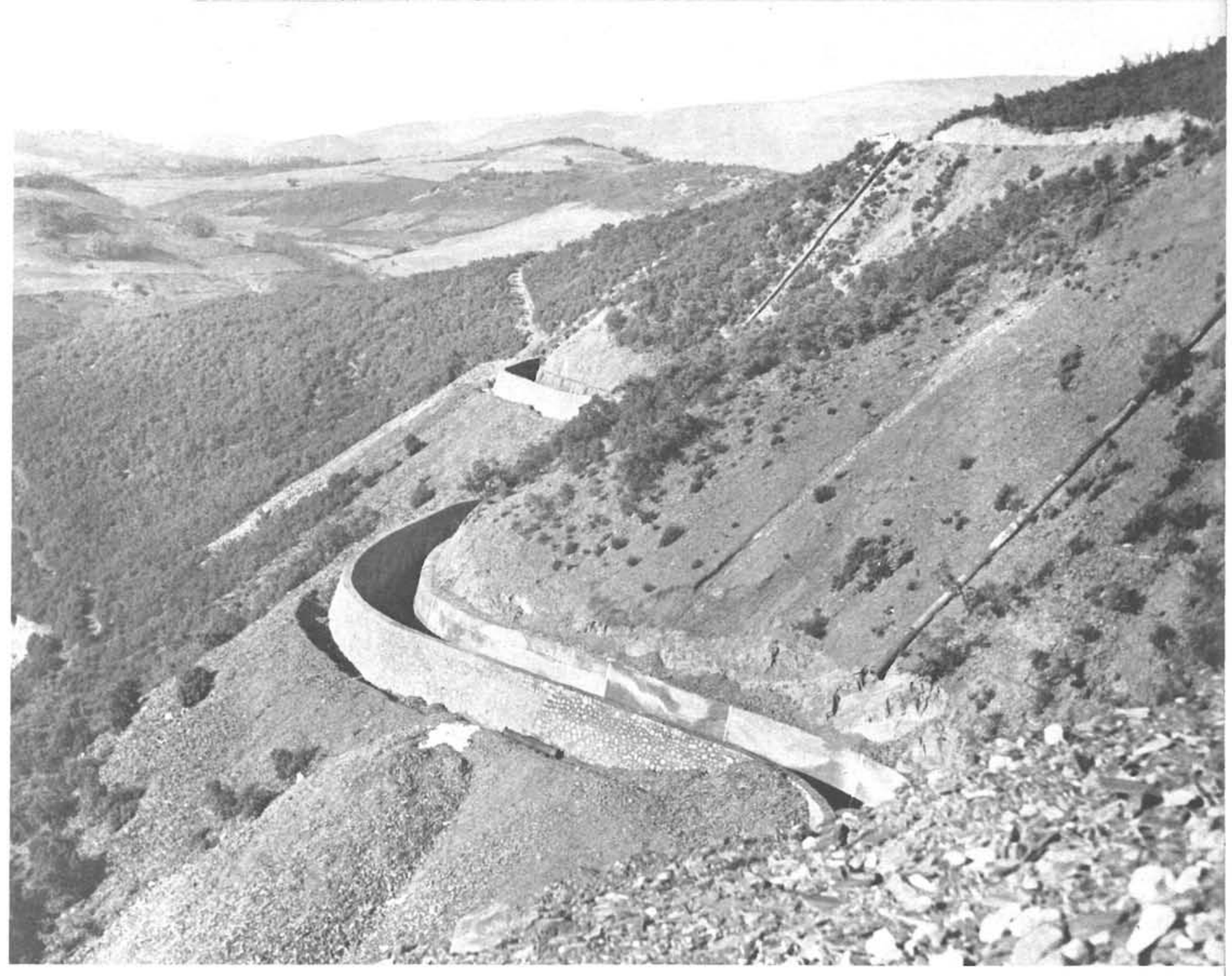

de un primitivo lago terciario, cuyo fondo constituye el actual valle, para unirse, unos kilómetros más abajo, con el rio Cabrera también de fuerte perfil hidráulico y que, como el Sil, es probable proceda de una captación: en este caso la de la cuenca alta del río Eria. Con este afluente se desvía nuevamente en dirección EO. para entrar en el ancho valle de Valdeorras.

Toda esta región abunda en recuerdos históricos. Los restos de las galerías de minas que se encuentran en la región de las Médulas, situada entre el Sil y el Cabrera, las canalizaciones que parten de este río para llevar las aguas hasta los lavaderos de mineral y las secciones para canal en roca que pueden verse en ambas márgenes del rio, cerca de la presa de Fuente del Azufre, dan idea de la actividad que pudo haber en épocas romanas. Las construcciones actualmente en ruinas, de castillos, iglesias y monasterios en Ponferrada, Congosto, Cornatel, Bembibre, San Miguel de las Dueñas, Villaverde de la Abadía, Santo Tomás de las Ollas, y tantas otras poblaciones, recuerdan a los reyes leoneses y a la Orden del Temple.

El aprovechamiento hídroeléctrico de la zona ha sido otorgado a la Empresa Nacional de Electricidad, desde el valle de Bárcena a la confluencia del Cabrera.

A partir del valle de Valdeorras, el río se encajona de nuevo en el famoso Montefurado, y, habiéndose engrosado con otros afluentes, se abre después de la confluencia del Quiroga por San Clodio, pero cambia bruscamente al atravesar la fragosa región cercana a Monforte de Lemos, de cuyas altiplanicies recibe al Cabe, después del cual se une al Miño en el lugar llamado Barcas de Peares.

\section{Sus afluentes}

Recibe los más importantes afluentes en las proximidades o en los propios ensanchamientos. De esta forma: el Caboalles, en el valle de Laceana; el Boeza, Cúa y Burbia, en el valle del Bierzo; el Cabrera, muy próximo, en el ensanchamiento de Quereño, y el Quiroga, por San Clodio.

Todos ellos presentan características parecidas al río principal. Nacen generalmente en picos de alturas próximas a los dos mil metros y, especialmente los de la cuenca alta hasta el Cabrera, atraviesan terrenos de pizarras silúricas, de la época carbonifera, y manchas devónicas, donde se forman algunos ensanchamientos aptos, en general, para embalses. En su gran mayoría permiten formación de embalses para almacenar el agua uue no puede retenerse en el Sil. El más importante ha sido estudiado por los Servicios Hidráulicos del Norte de España en el río Boeza, por la construcción de una presa en las cercanías 


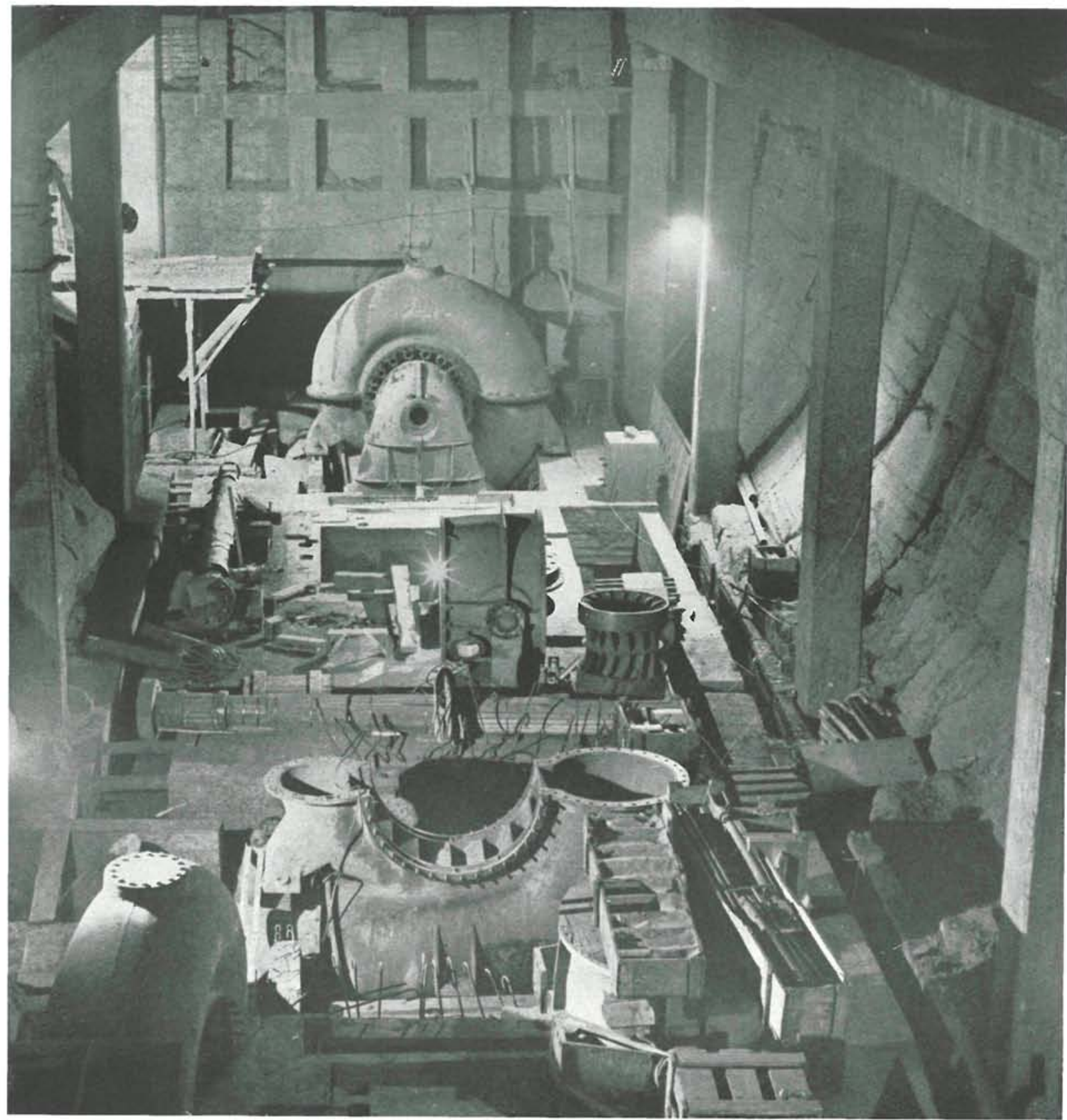

de San Miguel de las Dueñas. Unido por medio de un tủnel de trasvase al pantano de Bárcena, permitiria regular por completo las aportaciones de ambos ríos, invirtiendo su régimen en toda la cuenca alta, con lo que convertiria todas las centrales instaladas en ella en productoras de energia de verano y mejoraría notablemente la producción del resto de las instalaciones del Sil e incluso del Miño.

Otros de menor capacidad, como por ejemplo el de la cabecera del Cúa, permitirían mejoras importantes, especialmente si sus caudales fueran utilizados en el riego del alto Bierzo, pasando las aguas del Sil a incrementar la producción eléctrica de sus saltos.

\section{Los caudales}

La cuenca del alto Sil es, hidráulicamente, una de las mejores de España. Aunque el régimen es pluvial, sus lluvias son abundantes y se cambian en nieve durante los meses de invierno, que constituye fuertes reservas en los montes donde nace el río y sus afluentes, La pendiente, muy pronunciada en las laderas, la impermeabilidad de éstas, constituidas en su mayor parte, como se ha dicho, por pizarras y cuarcitas, la escasa vegetación $y$, en general, la pequeña evaporación, dan lugar a un elevado coeficiente de esla escasa
correntía.

El régimen del río corresponde, en año normal, a un período de lluvias de primavera, que, cuando coincide con el deshielo, da lugar a grandes avenidas, a partir de las cuales el caudal decrece hasta alcanzar sus mínimos a finales de verano (en los meses de septiembre y octubre), en que se producen las lluvias de otoño. Algunas veces, con cierta frecuencia, el estiaje se prolonga hasta noviembre o diciembre, por retrasarse estas lluvias y caer en forma de nieve en las alturas; pero, generalmente, son estos 


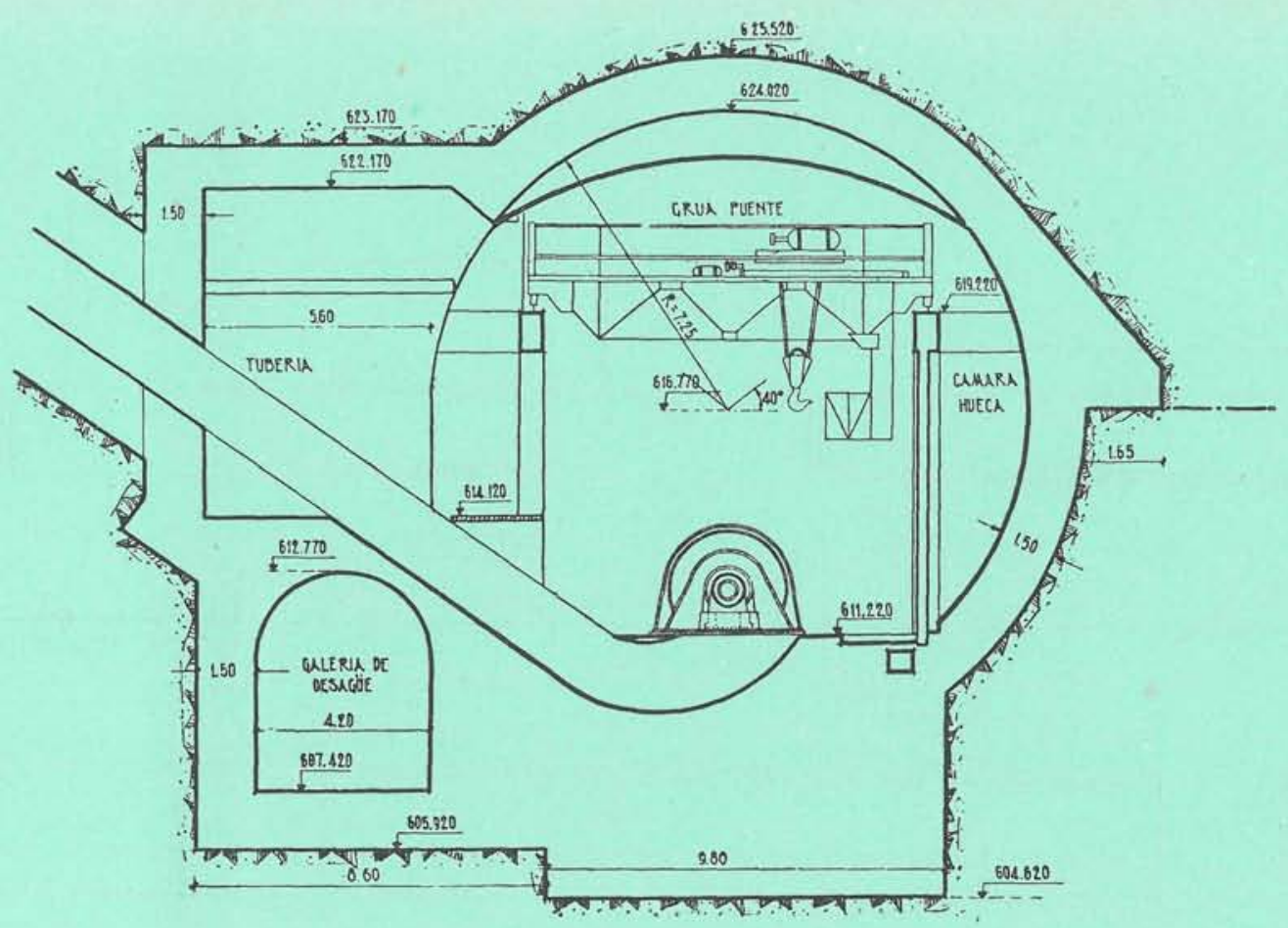

sección

dos meses los de máximos caudales continuos. Después, las aportaciones disminuyen y el rio suele presentar un mínimo relativo en enero.

Creemos interesante el siguiente cuadro, que nos indica las aportaciones medias anuales del sil $y$ sus afluentes de la cuenca alta:

Sil en Villablino:

$305 \mathrm{Hm}^{2}$

Sil en Ponferrada:

$835 \mathrm{Hm}^{2}$

Sil en Toral de los Vados:

$1.510 \mathrm{Hm}^{3}$

Sil en Quereño:

$3.190 \mathrm{Hm}^{3}$
Caboalles:

$175 \mathrm{Hm}^{2}$

Boeza :

$525 \mathrm{Hm}^{2}$

Cúa-Burbia :

$1.450 \mathrm{Hm}^{3}$

Cabrera:

$405 \mathrm{Hm}^{3}$
RELACION

0,57

0,96

0,12

\section{Los aprovechamientos}

Como queda indicado más arriba, el aprovechamiento del Sil en su cuenca alta-entendiendo como tal hasta la confluencia del Cabrera-está concedido a dos Sociedades, filiales ambas del Instituto Nacional de Industria: la Compañía Hidroeléctrica de Galicia y la Empresa Nacional de del Instituto Nacional de Industria: la Compañía Hidroeléctrica de Galicia y la Empresa Nacional de Electricidad. Tiene la
primera el tramo de rfo desde la confluencia con el Caboalles, en las inmediaciones de Villablino y a la cota 959,50 hasta el pantano de Bárcena, cuya cota de máximo embalse es la 620 , y divide los trescientos cuarenta metros de desnivel bruto en tres saltos. La segunda obtuvo sus primeras concesiones como consecuencia de la construcción de la Central Térmica de Ponferrada, por la que le fueron otorgados los aprovechamientos de los saltos de pie de presa de Bárcena y Fuente del Azufre, aguas arriba de esta ciudad, proyectadas por los Servicios Hidreulicos del Norte para el riego del alto y bajo Bierzo. Posteriormente ha la construcción de los saltos de Cornatel y Quereño y, en la actualidad, estudia las posibilidades del
Boeza, Cúa, Burbia y Cabrera para perfeccionar su sistema.

\section{Hidroeléctrica de Galicia}

Tiene la concesión de una zona de fuertes lluvias y acusados desniveles, con terreno impermeable de acusadas pendientes y gran escorrentía, en el que las isoietas varian desde $1.500 \mathrm{~mm}$ en las alturas a 900 en los llanos. 


\section{plantas \\ central subterránea}
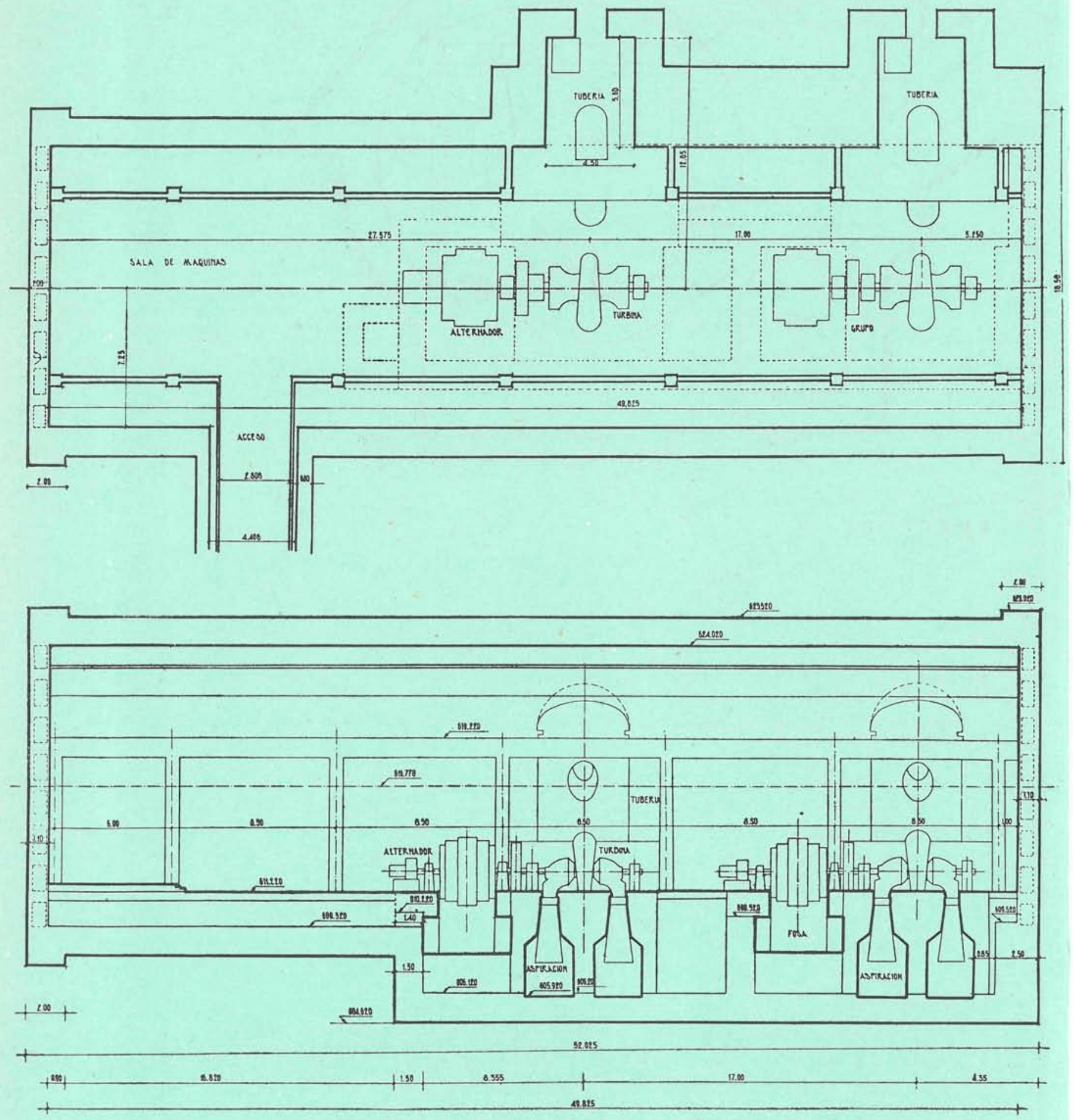

En el proyecto del sistema ha predominado la idea de buscar una regulación, difícil de encontrar en el Sil, ya que, aun cuando existen numerosas hoces y desfiladeros muy adecuados para la construcción de presas de gran altura, la necesidad de efectuar larges variantes en el ferrocarril Ponferrada-Villablino pequeño volumen de embalse que se obtiene, como consecuencia de la fuerte pendiente del rio y de la estrechez del cauce, hacen su coste prohíbitivo. La regulación para el salto número 3 , cabeza de los aprovechamientos, ha sido encontrada en el arroyo Valseco, afluente del Sil por su margen izquierda, y completada con un embalse de toma. 


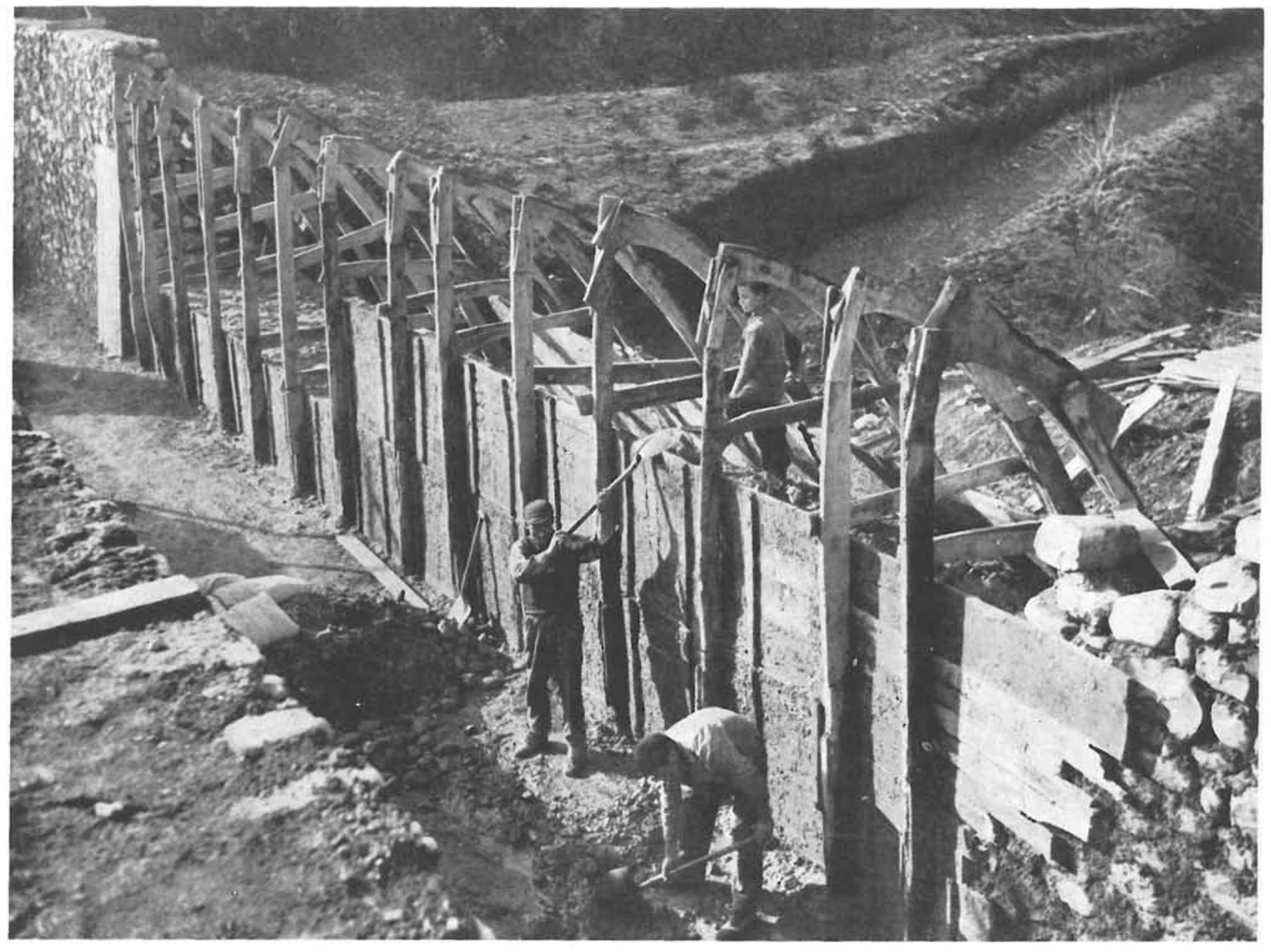

Mediante ambos, quedará regularizado el sistema que ha empezado a construirse por el salto número 1, casi terminado en la actualidad, cuyas turbinas desaguan en el embalse de Bárcena,

de la Empresa Nacional de Electricidad.

E1 salto número 3 toma las aguas en el embalse de las Rozas,

obtenido sobre el Sil por medio de una presa de contrafuertes,

de $46,75 \mathrm{~m}$ de altura,

la cual, con un nivel máximo de cota 959.50 ,

tendrá una capacidad útil de cerca de $28 \mathrm{Hm}^{3}$. Una galería en carga, de más de diez kilómetros de longitud,

llevará las aguas al embalse de Matalavilla, sobre el río Valseco,

formado por una presa bóveda de $82 \mathrm{~m}$ de altura,

con una capacidad útil de $42,5 \mathrm{Hm}^{3}$ y nive! de aguas a la cota 957,80
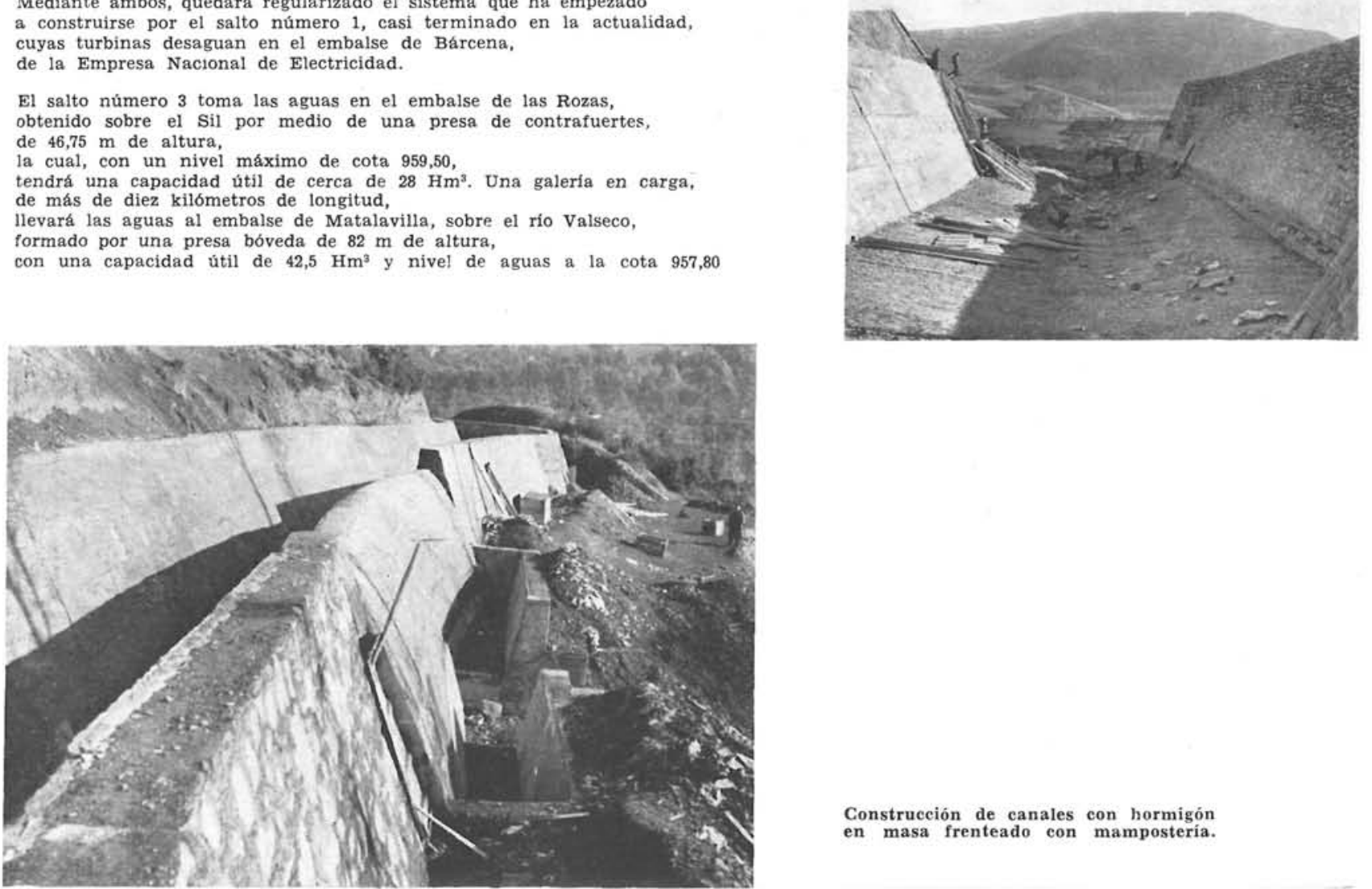

Construcción de canales con hormigón en masa frenteado con mampostería. 


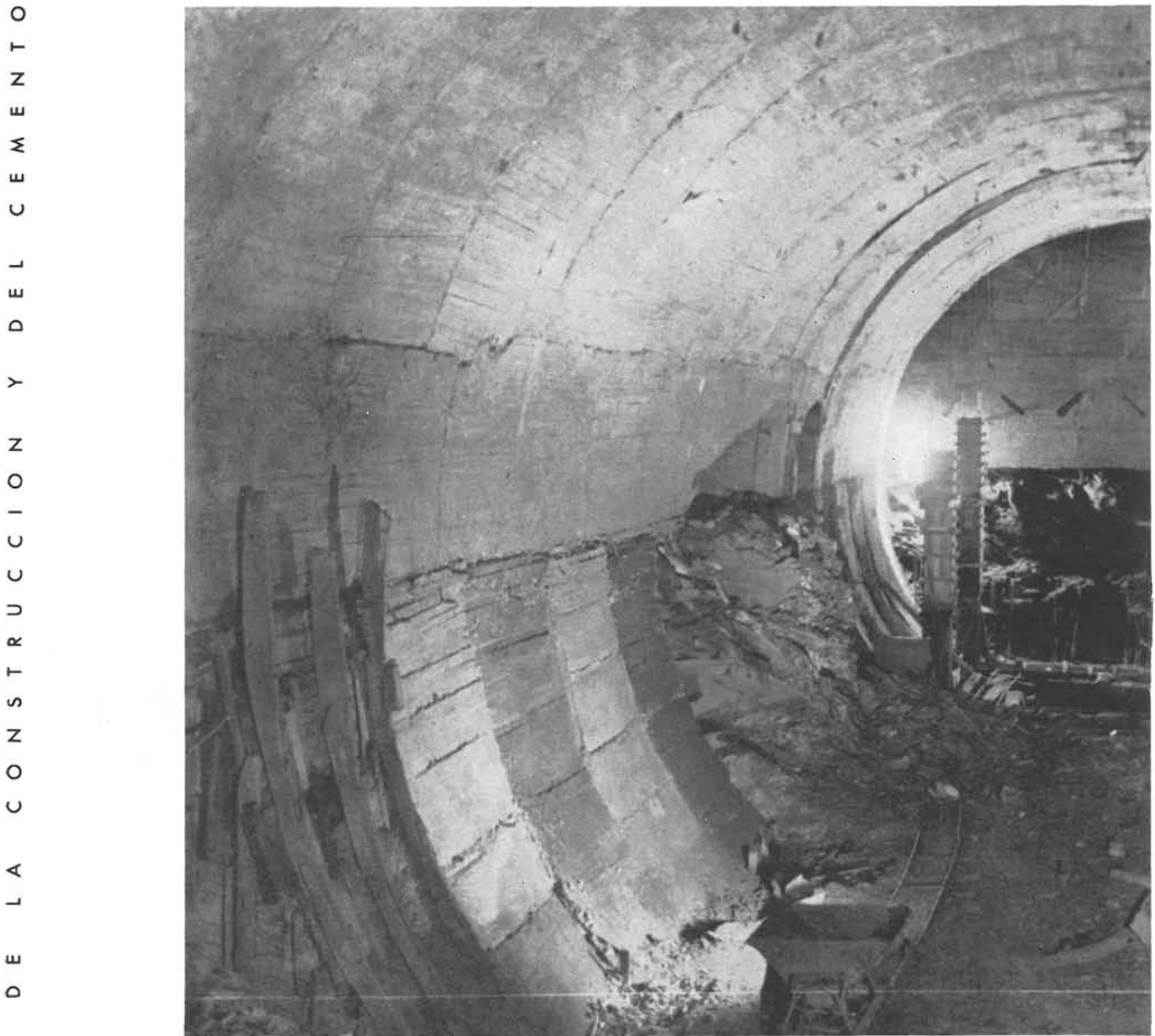

o

Desde el, por una galería en carga, de $4,60 \mathrm{~m}$ de diámetro, capaz de un caudal de $60 \mathrm{~m}^{3} / \mathrm{s}$, pasarán las aguas a la futura central de las Ondinas, situada en la margen izquierda del Sil, que se equipará con dos grupos de 41.500 KVA cada uno.

La central de Ondinas restituirá sus aguas en el contraembalse del mismo nombre, de $0,5 \mathrm{Hm}^{3}$ de ca pacidad, en el que se aplanarán las puntas dadas por la central, habiéndose proyectado en él una toma para el canal del salto número 2, capaz de $50 \mathrm{~m}^{3} / \mathrm{s}$, que se construirá apoyándose sobre la margen derecha del Sil, captando los diferentes arroyos que atravesará mediante pequeñas obras de derivación.

El canal desemboca en un pequeño depósito de regulación, del que parten dos tuberías forzadas-una para cada grupo-, que llegan a la central de Peñadrada, donde serán instalados dos grupos de 19.200 KVA cada uno.

Las turbinas de esta central desaguarán en el pequeño contraembalse de Peñadrada, situado en las inmediaciones de Matarrosa, donde tiene su toma el salto número 1 (que describiremos con más minuciosidad por tratarse de una obra que entrará en servicio en breve plazo).

El aprovechamiento de Santa Marina está formado, en síntesis, por una conducción que se desarrolla casi totalmente en canal, extendiéndose a lo largo de la margen derecha del sil en una longitud de unos nueve kilómetros, hasta las inmediaciones del pueblo de Toreno, donde cruza la carretera de PonferradaLa Espina. formando un sifón de ochenta metros de longitud, para alcanzar la ladera del arroyo de Valdelaloba, cuya margen izquierda sigue el canal hasta llegar al Sil. 


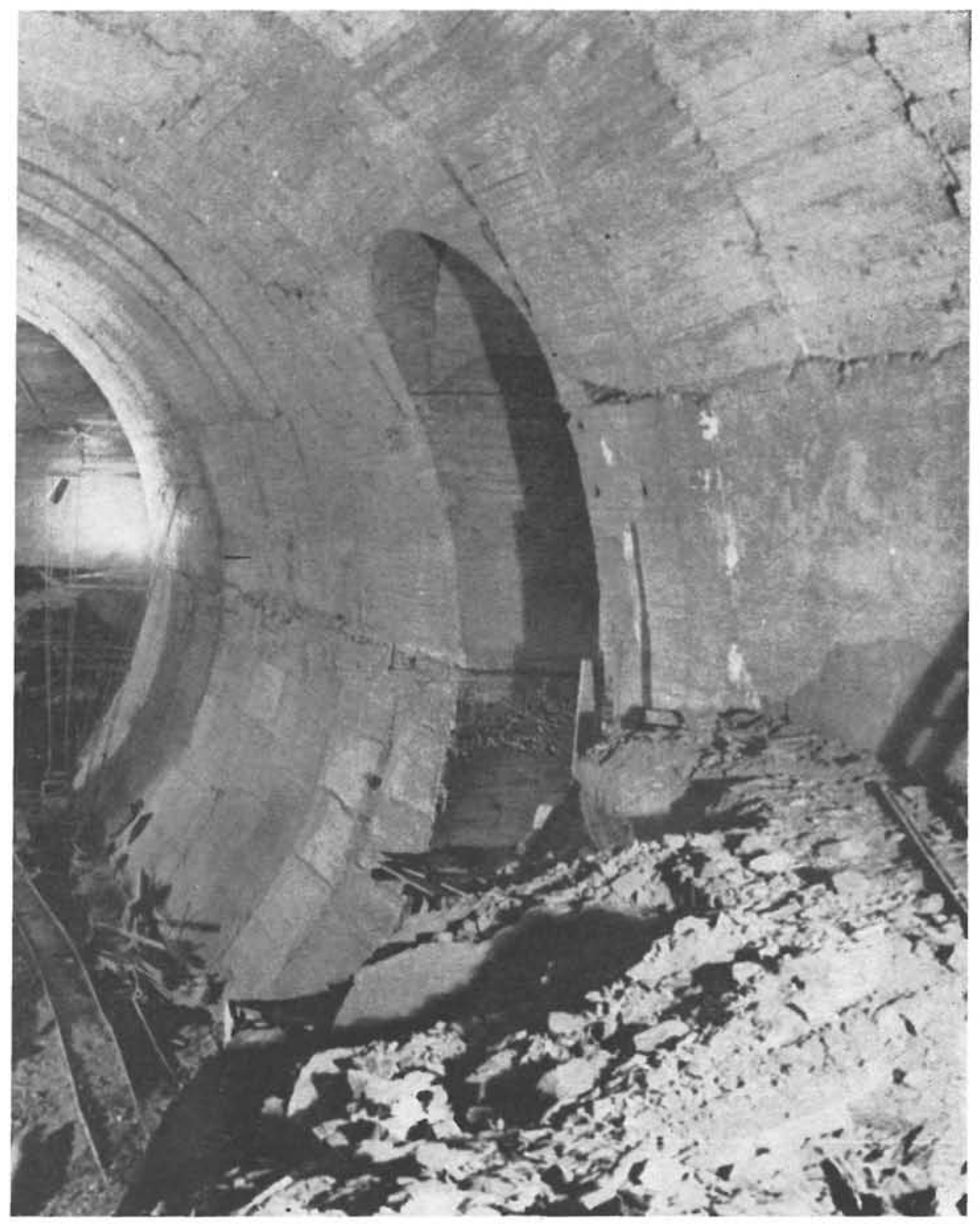

La conducción, con un trazado total de más de doce kilómetros, termina en una cámara de regulación, que, con una longitud de $185 \mathrm{~m}$, una anchura variable de 15 a $26 \mathrm{~m}$ y una profundidad que aumenta de 6 a $9 \mathrm{~m}$, almacena $18.500 \mathrm{~m}^{3}$. Desde ella pasa el agua a una central subterránea por medio de un pozo vertical que alimenta dos grupos.

Se ha pensado utilizar la central de este salto como base de producción del sistema, para lo cual el embalse de Peñadrada debe lamínar los caudales de puntas de la central del salto número 2, de tal forma que deje pasar por el canal de toma $20 \mathrm{~m}^{3} / \mathrm{s}$ en régimen normal y un caudal máximo de $26 \mathrm{~m}^{3} / \mathrm{s}$, para el que ha sido proyectada la central, a fin de adaptarse a las variaciones de régimen del río. La central de Santa Marina se ha equipado con dos grupos gemelos de 12.000 KVA cada uno.

Las obras más importantes de este salto son: el conjunto de la casa de máquinas, depósito de regulación, pozo en carga y azud de derivación.

La presa de este salto se apoya sobre roca poco profunda y de suficiente resistencia. Ha sido proyectada formando un tramo central de $13,50 \mathrm{~m}$ de longitud y dos vanos laterales cerrados por compuertas de $12 \mathrm{~m}$ de luz cada una, de una capacidad de $1.200 \mathrm{~m}^{3} / \mathrm{s}$; su altura es de $3,50 \mathrm{~m}$ sobre el río en su paramento de aguas arriba, y ha sido ejecutado por bloques ataguiando el recinto en el que debía trabajarse.

La central se ha construído formando una cámara subterránea. Los tubos de aspiración de las turbinas van a dar a una galería general de descarga. En el proyecto se han tenido en cuenta las variaciones de nivel del pantano de Bárcena, por lo que se ha equipado la central con máquinas que pueden trabajar normalmente con doce metros de contrapresión, es decir, dentro de las variaciones del nivel de embalse comprendidas entre las cotas 608 y 620 . 


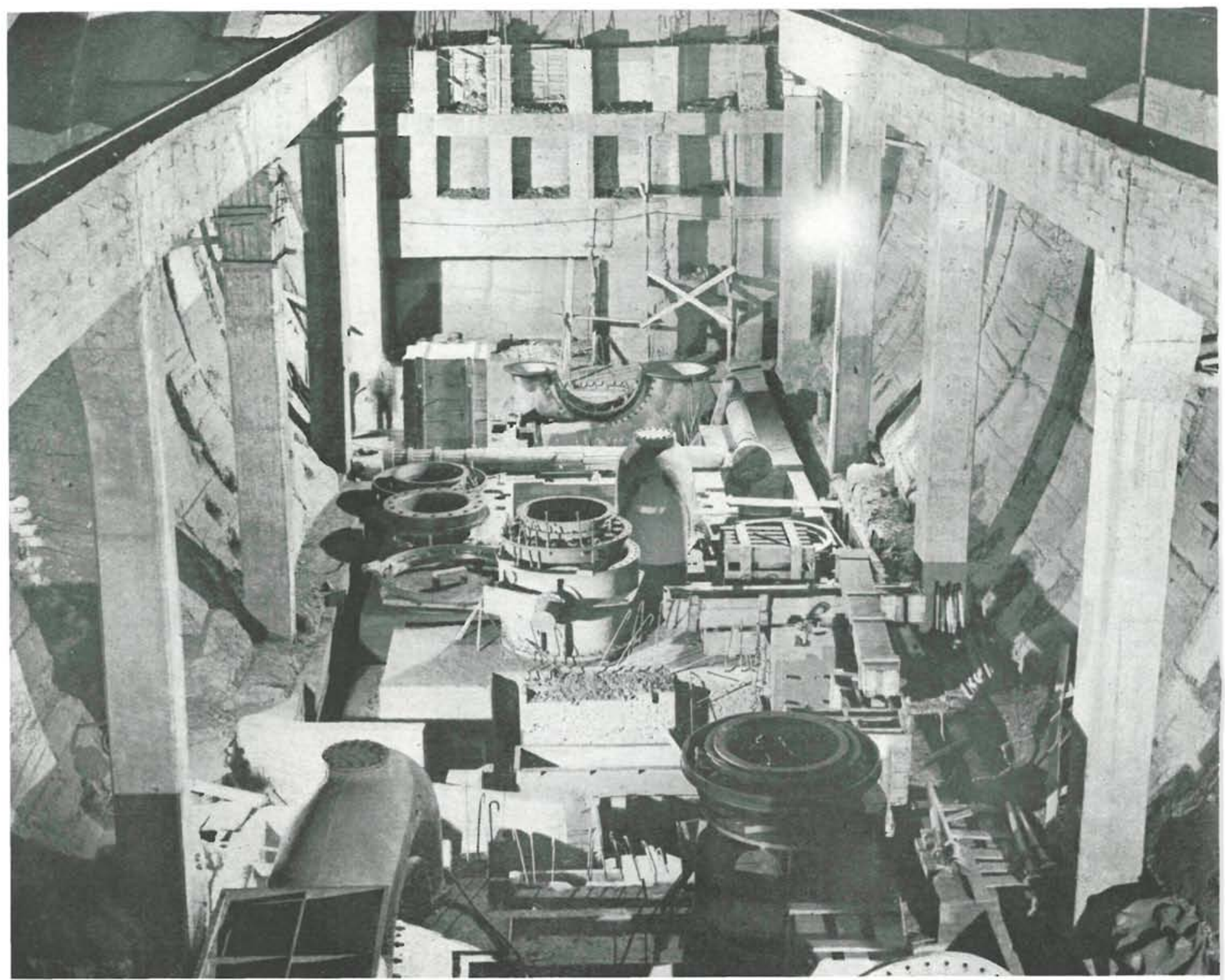

El hueco de la central se ha excavado en un terreno de pizarras, y, en previsión de una posible descomposición de éstas, la cámara tiene una sección circular, cuya parte superior forma una bóveda de $1,50 \mathrm{~m}$ de espesor. En el interior del espacio cilíndrico resistente de la central se ha formado la sala de máquinas, construyendo dos muros laterales para apoyo de las vigas de carrera del puente grúa y una bóveda rebajada sobre ellos, que sirven, en conjunto, como aislante contra la humedad y de alojamiento de las canalizaciones del sistema de ventilación del edificio.

\section{Funcionamiento y producción del sistema}

El conjunto de saltos ha sido concebido para que el salto número 1 funcione como base del sistema, mientras que los otros dos deben generar energia de puntas, especialmente el 3 . Este funcionamiento se ajusta a las caracteristicas de los saltos.

El embalse de Peñadrada permite a la central número 2 dar puntas de tres horas a plena carga, separadas por un intervalo igual de vaciado. Su función es regular el caudal de toma del salto número 1 y permitirle trabajar en base con un gasto, casi constante, de $20 \mathrm{~m}^{3} / \mathrm{s}$, y además en el periodo de estiaje per-

El embalse de las Ondinas tiene $0,5 \mathrm{Hm}^{3}$, doble capacidad que el de Peñadrada. Ello está plenamente justificado por el mayor caudal de la central número 3 y para tomar y almacenar, si fuera preciso, las justificado por el mayor no provienen de los embalses de Matalavilla y Las Rozas. Además se prevé una futura ampliación de la potencia instalada en la central número 3 , pasando de $60 \mathrm{~m}^{3} / \mathrm{s}$ a 90 , lo que haría bajar las horas de utilización de la central de 2.000 a 1.500 , a costa de una disminución en la producción, por pérdidas de carga, de unos $3,7 \times 10^{6} \mathrm{~kW} / \mathrm{h}$ anuales.

Como complemento de estas notas, adjuntamos las curvas de producción diarias y anuales que podrá proporcionar el sistema una vez terminada su construcción. 